\title{
Prevention of nitroimidazole resistance in Campylobacter pylori by coadministration of colloidal bismuth subcitrate: clinical and in vitro studies
}

\author{
C S GOODWIN,* B J MARSHALL, $\dagger$ E D BLINCOW,* D H WILSON,* \\ S BLACKBOURN, $\ddagger$ M PHILLIPS $₫$
}

From the Departments of *Microbiology, $†$ Gastroenterology and $\ddagger$ Pharmacy, Royal Perth Hospital, Perth, and Ithe Medical Statistics Department, Curtin University of Technology, Bentley, Western Australia

SUMMARY One hundred patients with duodenal ulceration and Campylobacter pylori in their stomach were entered into a double blind placebo controlled prospective study. Treatment schedules were cimetidine and placebo, or cimetidine and tinidazole, or colloidal bismuth subcitrate (CBS) and placebo, or CBS and tinidazole. Seventeen per cent of isolates of $C$ pylori obtained at the first endoscopy were resistant to tinidazole and $70 \%$ of the second isolates from patients given cimetidine and tinidazole became tinidazole resistant. Suspensions of nitroimidazole sensitive cultures of $C$ pylori showed that three of 22 isolates had a nitroimidazole resistant subpopulation. In patients who healed and remained free of $C$ pylori after treatment ulcers recurred less often than in patients who healed but retained $C$ pylori $(23 \% v 73 \%$ over 12 months, $\mathrm{p}<0.001)$.

The spiral bacteria first cultured from the gastric mucosa of patients with histologically confirmed gastritis at Royal Perth Hospital in $1982^{1}$ were originally named Campylobacter pyloridis, ${ }^{2}$ but the revised name is now Campylobacter pylori. ${ }^{3} \mathrm{C}$ pylori is highly susceptible to many antibiotics. ${ }^{245}$ We recently concluded a double blind, placebo controlled, prospective study of patients with duodenal ulceration and $C$ pylori in their stomach, which included the nitroimidazole drug (tinidazole), given in addition to standard prophylaxis. We report the development of tinidazole resistance in a high proportion of the patients given tinidazole and cimetidine; the full clinical details of the study will be reported elsewhere. Some patients remained unhealed after 10 weeks of treatment and were then entered into an open study of various antibacterial regimens. Colloidal bismuth subcitrate (CBS) has a powerful bactericidal action against $C$ pylori; the minimum inhibitory concentration of bismuth of $C$ pylori is $8 \mathrm{mg} / \mathrm{l}^{5}$ and ultrastructural studies of the gastric mucosa 75 minutes after administration of CBS have shown that most bacteria seem to have been killed.

Accepted for publication 21 July 1987

\section{Material and methods}

PLACEBO CONTROLLED STUDY

Patients referred to one of us (BJM) for upper gut symptoms were examined endoscopically, and if a duodenal ulcer was seen gastric mucosal specimens were taken for histological examination and culture of C pylori. Biopsy specimens were examined by Gram stain and culture in the manner already described. ${ }^{6}$ Patients found to have a duodenal ulcer with $C$ pylori (100 of 107 examined) were allocated to one of four treatment groups:

1 Cimetidine $400 \mathrm{mg}$ twice daily for eight weeks, plus placebo for the first 10 days.

2 Cimetidine for eight weeks plus tinidazole $500 \mathrm{mg}$ twice daily for the first 10 days.

3 CBS one tablet four times daily for eight weeks plus placebo for 10 days.

4 CBS for eight weeks plus tinidazole for the first 10 days.

Cimetidine is inactive against $C$ pylori. ${ }^{5}$ The patients were allocated their drug treatment randomly by a computer program to ensure that similar types of patients of the same sex, age, previous duodenal ulcer history, and drug treatment were in each of the four groups. 
OPEN STUDY

Each patient was examined endoscopically two, 14,26, and 52 weeks after the end of the initial course of treatment, and at any time when gastric symptoms were experienced which suggested relapse of the duodenal ulcer. At any of these endoscopies, if a duodenal ulcer was found the patient was removed from the double blind study and entered into an open study of CBS for 14 days plus either oral amoxycillin $500 \mathrm{mg}$ six hourly for seven or 14 days, or oral enteric coated pellets of erythromycin base $500 \mathrm{mg}$ six hourly for 14 days.

\section{SENSITIVITY TESTS}

Isolates of $C$ pylori were tested by disc diffusion on blood agar for their sensitivity to tinidazole $(5 \mu \mathrm{g})$, metronidazole $(5 \mu \mathrm{g})$, and amoxycillin $(2 \mu \mathrm{g})$. Sensitive strains were shown by a zone of inhibition of $25 \mathrm{~mm}$, and resistant isolates gave no zone of growth inhibition.

The minimum inhibitory concentrations (MICs) of tinidazole and metronidazole against isolates from eight patients, before and after the development of resistance, were determined by a method already described. ${ }^{5}$ To determine the prevalence of a subpopulation of tinidazole resistant bacteria within a sensitive culture 22 tinidazole sensitive strains were grown in liquid medium with shaking for 24 hours in a Campylobacter gas mixture. Then $0.6 \mathrm{ml}$ was inoculated on to agar containing $8 \mathrm{mg} / 1$ metronidazole or $8 \mathrm{mg} / \mathrm{l}$ tinidazole. The plates were incubated in a Campylobacter gas mixture for five days, and colonies which grew were tested for their sensitivity to the nitroimidazoles.

\section{Results}

Among the 100 isolates of $C$ pylori obtained at the first endoscopies 17 were resistant to tinidazole and metronidazole; these included two in the group treated with cimetidine and tinidazole and five in the group treated with CBS and tinidazole. In the 27 other patients in the group treated with cimetidine and tinidazole the isolate became resistant in $19(70 \%)$. In the 27 patients who received CBS and tinidazole the original isolate was tinidazole resistant in five patients, and $C$ pylori was not eliminated in four of these patients. In the remaining 22 patients $C$ pylori was eliminated in 20 , and the isolate became tinidazole resistant in the other two.

Elimination of $C$ pylori from the stomach was achieved in only one of the 29 patients who received cimetidine and tinidazole. This was significantly different $\left(\mathrm{p}<0.001, \chi^{2}=55.4\right)$.

The isolate of $C$ pylori that was sensitive at entry into the trial from eight patients was compared with the isolate from the second biopsy specimen whicho showed nitroimidazole resistance. For the sensitive isolates the MICs to both metronidazole andtinidazole were less than $4 \mathrm{mg} / \mathrm{l}$, and the MICs of resistant isolates were $16 \mathrm{mg} / \mathrm{l}$ or greater.

Twenty two cultures of $C$ pylori in liquid mediume were plated on solid medium containing metro- $\overline{\bar{n}}$. nidazole or tinidazole $8 \mathrm{mg} / \mathrm{l}$. After five days of incubation three of the cultures showed between 100 , and 200 colonies of $C$ pylori on each plate. The ${ }^{\infty}$ resistances were confirmed by disc diffusion and $\overrightarrow{0}$ determination of MIC.

\section{PLACEBO CONTROLLED STUDY}

The computer program allocated 22 patients to receive cimetidine and placebo, 29 to receive cimetidine and tinidazole, 22 to receive CBS and placebo, and 27 to receive CBS and tinidazole. In the open study 150 patients received CBS plus amoxycillin for seven days,o 25 patients received CBS plus amoxycillin for 14 days, and 18 patients received CBS plus erythromycin for 14 days.

The addition of antibacterial treatment to antiulcer treatment did not give a higher initial healing rate of duodenal ulcer in the various groups. Thirty three of $\overrightarrow{ }$ the 100 patients remained unhealed after the eighto weeks, 36 relapsed after healing, and 31 remained $^{\infty}$ healed for 12 months. Initial healing was accompaniedo by elimination of $C$ pylori in 26 patients, and in six of these the duodenal ulcer recurred. In 41 patients theo duodenal ulcer healed but $C$ pylori were still present, $\frac{\mathrm{O}}{\mathrm{O}}$ and in 30 patients the duodenal ulcer recurred. This $\varrho$ was highly significant $(\mathrm{p}<0.001)$. Clearance of $\overrightarrow{0}$ $C$ pylori in 28 patients was accompanied by ulcer 3 healing in 26, but only 41 of the patients who remained infected with $C$ pylori showed ulcer healing $(\mathrm{p}<0.001)$.

\section{OPEN STUDY}

The healing rates of the duodenal ulcers and the number of patients in whom $C$ pylori was eliminated are shown for the three antibiotic regimens in the table. Eighteen patients were given erythromycin but one patient developed severe side effects so that he could take no more than two days of treatment. Interestingly, amoxycillin plus CBS for 14 days $\stackrel{N}{N}$

Healing of duodenal ulceration and elimination of $C$ pylori in patients treated with $C B S$ and antibiotic

\begin{tabular}{llll}
\hline & $\begin{array}{l}\text { No of } \\
\text { patients }\end{array}$ & $\begin{array}{l}\text { Ulcer } \\
\text { healed (\%) }\end{array}$ & $\begin{array}{l}\text { Cpylori } \\
\text { eliminated(\%) }\end{array}$ \\
CBS plus: & 15 & $13(87)$ & $7(47)$ \\
$\begin{array}{l}\text { Amoxycillin for seven } \\
\text { days }\end{array}$ & $17(68)$ & $11(44)$ \\
$\begin{array}{l}\text { Amoxycillin for 14 days } 25 \\
\text { Erythromycin }\end{array}$ & 17 & $15(88)$ & $11(65)$ \\
\hline
\end{tabular}


achieved about the same elimination rate as amoxycillin plus CBS for seven days.

All the patients treated with tinidazole remained free of systemic side effects, but some complained of a metallic taste in the mouth. A few patients treated with amoxycillin complained of abdominal discomfort and a few of diarrhoea. After endoscopy patients developed symptoms which could be attributed more to endoscopy than to antibiotic, and if the patients persisted taking the antibiotic their symptoms receded. Seven patients treated with erythromycin complained bitterly of abdominal pain.

\section{Discussion}

In the double blind placebo controlled prospective trial tinidazole was chosen as the antibacterial agent for several reasons. Previous experience indicated that patients who already complained of indigestion did not experience any additional symptoms when given tinidazole. Bismuth plus tinidazole had proved the most effective of various combinations in a preliminary study. It was known that a small proportion of isolates of $C$ pylori were resistant to tinidazole, but our finding that tinidazole plus cimetidine resulted in $70 \%$ of the isolates becoming resistant to tinidazole was unexpected. We also found that in the absence of tinidazole, when $C$ pylori had not been eliminated, the subsequent isolates of $C$ pylori occasionally became tinidazole resistant. Thus resistance can occur spontaneously, and this was confirmed by our studies in vitro; when cultures of nitroimidazole sensitive $C$ pylori were plated on agar containing nitroimidazole, three of 22 culture growths showed large numbers of nitroimidazole resistant colonies on the agar. Nine of these resistant strains were retested after subculture on to plain media without antibiotics and one strain reverted to nitroimidazole sensitivity. This is reminiscent of rifampicin resistance and fusidic acid resistance in cultures of susceptible bacteria, when most cultures exhibit a small proportion of bacteria resistant to these antibiotics. Thus a nitroimidazole drug should never be given as the sole antibacterial treatment for $C$ pylori, but when combined with CBS, nitroimidazole resistance did not occur so often; and in $84 \%$ of patients $C$ pylori was eliminated.

The minimum inhibitory concentration of metronidazole against $C$ pylori was reported by McNulty et al to be $0.5-8.0 \mathrm{mg} / \mathrm{l}$ on solid media. ${ }^{4}$ In liquid medium we found that the $\mathrm{MIC}_{90}$ was $4.0 \mathrm{mg} / \mathrm{l}$, the minimum bactericidal concentration for $90 \%$ of isolates was $16 \mathrm{mg} / \mathrm{l}$, and isolates resistant to tinidazole had an $\mathrm{MIC}_{90}$ of $32 \mathrm{mg} / \mathrm{l}^{5}$ In the present study the $\mathrm{MIC}_{90}$ of tinidazole against resistant isolates was 16 $\mathrm{mg} / \mathrm{l}$ or greater.

The principal problem encountered in the treatment of duodenal ulcers is the relapse rate, which can be as high as $100 \%$ in patients followed up for two years. ${ }^{8}$ In our double blind study recurrence of the duodenal ulcer after initial healing was detected by endoscopy in $73 \%$ of 41 patients in whom $C$ pylori had not been eliminated, but when healing was accompanied by elimination of $C$ pylori only six $(23 \%)$ of patients relapsed $(\mathrm{p}<0.001)$.

Thus effective antibacterial treatment with the elimination of $C$ pylori significantly reduces the relapse rate of healed duodenal ulcers. We also found that initial clearance of $C$ pylori was accompanied by ulcer healing in $26(93 \%)$ of 28 patients, but when patients remained infected with $C$ pylori only $41(57 \%)$ showed ulcer healing $(\mathrm{p}<0.001)$.

In the open study of TCB plus amoxycillin for 14 days $C$ pylori was eliminated in less than seven $(50 \%)$ of the patients. Beta lactam producing antibiotics penetrate cells less efficiently than other antibiotics 9 and $C$ pylori does not invade the gastric mucosa but is found on the surface of the mucosa, and so may be even less accessible to amoxycillin. Erythromycin penetrates cells better than amoxycillin and in 11 $(65 \%)$ of patients we were able to eliminate $C$ pylori. It is clear that a dual treatment regimen with CBS plus an appropriate antibiotic is much more effective at eliminating $C$ pylori than either treatment with only CBS or an antibiotic alone. ${ }^{10-12}$ The organism lives in a sequestered niche ${ }^{12}$ and thus repeated courses of antibiotics may be required to eliminate it.

We acknowledge a grant from the National Health and Medical Research Council of Australia for Dr B J Marshall. We thank Pfizer for supplies of tinidazole, placebo antibiotic and financial assistance. We thank Faye Coverley for secretarial help.

\section{References}

1 Marshall BJ, Warren JR. Unidentified curved bacilli in the stomach of patients with gastritis and peptic ulceration. Lancet 1984;i:1311-5.

2 Marshall BJ, Royce H, Annear DI, et al. Original isolation of Campylobacter pyloridis from human gastric mucosa. Microbios Letters 1984;25:83-8.

3 Marshall BJ, Goodwin CS. Revised nomenclature for $\mathrm{C}$ pyloridis. Int J Systems Bacteriol 1987;37:68.

4 McNulty CAM, Dent J, Wise R. Susceptibility of clinical isolates of Campylobacter pyloridis to 11 antimicrobial agents. Antimicrob Agents Chemother 1985;28:837-8.

5 Goodwin CS, Blake P, Blincow E. The minimum inhibitory and bactericidal concentrations of antibiotics and anti-ulcer agents against Campylobacter pyloridis. J Antimicrob Chemother 1986;17:309-14.

6 Goodwin CS, Blincow ED, Warren JR, Waters TE, Sanderson CR, Easton L. Evaluation of cultural techniques for isolating Campylobacter pyloridis from endoscopic biopsies of gastric mucosa. J Clin Pathol 1985;38:1127-31. 
7 Marshall BJ, Armstrong JA, Francis G, Nokes NT, Lee SH. The antibacterial action of Bismuth in relation to Campylobacter pyloridis colonization and gastritis. Digestion 1987;37(suppl 2): 16-30.

8 Bardhan K, Cole DS, Hawkins BW, Franks CR. Does treatment with cimetidine extended beyond initial healing of duodenal ulcer reduce the subsequent relapse rate? $\mathrm{Br}$ Med $J$ 1982;284:621-3.

9 Jacobs RF, Wilson CB. Intracellular penetration and antimicrobial activity of antibiotics. $J$ Antimicrob Chemother 1983;12(Suppl C):13-20.

10 Langenberg ML, Rauws EAJ, Schipper MEI, et al. The pathogenic role of Campylobacter pyloridis studied by attempts to eliminate these organisms. In: Pearson AD, Skirrow MB, Lior H, Rowe B, eds. Campylobacter III: proceedings of the third international workshop on Campylobacter infections. London: Public Health Laboratory Service, 1985:162-3.

11 McNulty CAM, Crump B, Gearty JC, et al. Campylobacter음 pyloridis and associated gastritis: investigator blind, placebo controlled trial of bismuth salicylate and erythromycin ethyl- $\overline{5}$ succinate. Br Med J 1986;293:645-9.

12 Goodwin CS, Armstrong JA, Marshall BJ. Campylobacter pyloridis, gatritis, and peptic ulceration. J Clin Pathol 1986 39:353-65.

Requests for reprints to: Professor C S Goodwin, Department of Microbiology, Royal Perth Hospital, Perth, Western. Australia. 